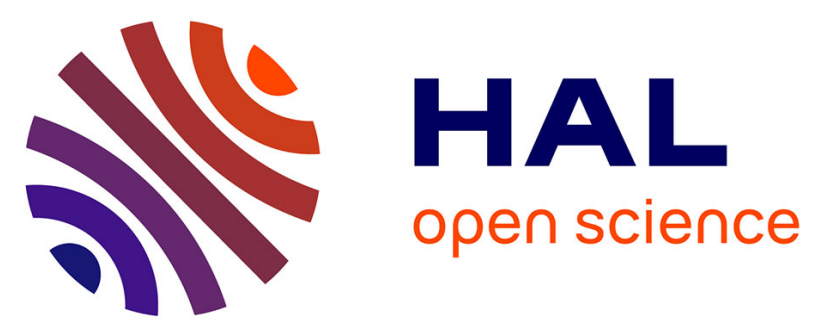

\title{
Population dynamics of pest mosquitoes and potential malaria and West Nile virus vectors in relation to climatic factors and human activities in the Camargue, France
}

Nicolas Ponçon, Celine Toty, Gregory L'ambert, Gilbert Le Goff, Cecile Brengues, Francis Schaffner, Didier Fontenille

\section{To cite this version:}

Nicolas Ponçon, Celine Toty, Gregory L'ambert, Gilbert Le Goff, Cecile Brengues, et al.. Population dynamics of pest mosquitoes and potential malaria and West Nile virus vectors in relation to climatic factors and human activities in the Camargue, France. Medical and Veterinary Entomology, 2007, 21 (4), pp.350-357. 10.1111/j.1365-2915.2007.00701.x . hal-03359124

\author{
HAL Id: hal-03359124 \\ https://hal.science/hal-03359124
}

Submitted on 30 Sep 2021

HAL is a multi-disciplinary open access archive for the deposit and dissemination of scientific research documents, whether they are published or not. The documents may come from teaching and research institutions in France or abroad, or from public or private research centers.
L'archive ouverte pluridisciplinaire HAL, est destinée au dépôt et à la diffusion de documents scientifiques de niveau recherche, publiés ou non, émanant des établissements d'enseignement et de recherche français ou étrangers, des laboratoires publics ou privés. 


\title{
Population dynamics of pest mosquitoes and potential malaria and West Nile virus vectors in relation to climatic factors and human activities in the Camargue, France
}

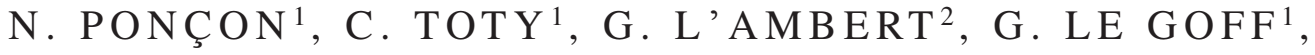 \\ C. BRENGUES ${ }^{1}$, F. SCHAFFNER ${ }^{2,3}$ and D. FONTENILLE ${ }^{1}$ \\ ${ }^{1}$ Department of Health, Research Unit 016, Institut de Recherche pour le Développement (IRD), Montpellier, France, ${ }^{2}$ Department of \\ Research and Development, Entente Interdépartementale pour la Démoustication (EID) Méditerranée, Montpellier, France and \\ ${ }^{3}$ Institute of Parasitology, University of Zürich, Zürich, Switzerland
}

\begin{abstract}
The Camargue is an extensive wetland in the southeast of France, which is highly influenced by human activities. Large ponds, marshes and irrigated fields provide abundant potential breeding sites for mosquitoes. Mosquitoes, which are important in terms of the nuisance they cause to people and animals, the limitations they impose on tourism and their potential threat to human health. Several of the mosquito species present are potential vectors of malaria and West Nile virus. Therefore, the population dynamics of these species were monitored over an entire breeding season during MarchOctober 2005. Mosquito populations were sampled in two study areas once every 2 weeks, using CDC light traps baited with $\mathrm{CO}_{2}$. Sixteen species were collected. The majority (98.7\%) of the catch were Aedes caspius (Pallas) (Diptera: Culicidae), Culex modestus (Ficalbi), Culex pipiens L. and Anopheles hyrcanus (Pallas). The population dynamics of these species varied considerably in relation to the species' biology, climatic conditions (rainfall, temperature and season), water management, implementation of mosquito control campaigns and landscape use.
\end{abstract}

Key words. Aedes caspius, Anopheles hyrcanus, Culex modestus, Culex pipiens, irrigation, population dynamics, France.

\section{Introduction}

The Camargue is an extensive wetland in the Rhone river delta, located in southern France. Most of its surface is covered by large ponds, marshes and irrigated fields. It is very famous for its beautiful landscapes, but also for an abundance of mosquitoes, which limits tourism in the area. In September 2005, for example, large populations of mosquitoes caused such a nuisance that tourists left the Camargue and schools were closed. Moreover, the potential impact of mosquitoes on human and animal health needs to be considered. Malaria was endemic in the Camargue until World War II, and, although there is currently no autochthonous transmission, potential vectors are still present in the Camargue, leading to an 'anophelism without malaria' situation (Rodhain \& Charmot, 1982; Ponçon et al., 2007a). Moreover, three suspected autochthonous malaria cases were described recently in southern France, supporting the supposition that the region remains suitable for malaria transmission (Armengaud et al., 2006; Doudier et al., 2007). Several, although limited, West Nile virus (WNV) outbreaks have been reported since 1960 in this area, and associated vectors were reported recently in the Camargue (Zeller \& Schuffenecker, 2004; Balenghien et al., 2006).

The abundance of potential vectors in the Camargue has varied greatly over the last 70 years. Environmental changes, mainly caused by anthropogenic practices, have had an impact on inter-annual variations in the abundance of mosquitoes (Ponçon et al., 2007b). The study presented here was undertaken

Correspondence: N. Ponçon, Institut de Recherche pour le Développement (IRD), UR016, Caractérisation et Contrôle des Populations de Vecteurs, 911 Avenue Agropolis, BP 64501, 34394 Montpellier Cedex 5, France. Tel.: + 3346704 19 24; Fax: + 3346754 20 44; E-mail: poncon@mpl.ird.fr 
to investigate the impact of environmental factors on the population dynamics of nuisance mosquito species and potential malaria and WNV vectors in the Camargue.

\section{Materials and methods}

Study area and location

The Camargue has a Mediterranean climate, characterized by warm, dry summers and mild, wet winters. Total annual rainfall range is usually $500-700 \mathrm{~mm}$, with a maximum during October. The annual mean temperature is $14^{\circ} \mathrm{C}$. Mean daily minimum and maximum temperatures range from $0^{\circ} \mathrm{C}$ to $10^{\circ} \mathrm{C}$ in winter and $15^{\circ} \mathrm{C}$ to $30^{\circ} \mathrm{C}$ in summer. The population dynamics of mosquitoes were investigated in two areas, representative of the main habitat types in the Camargue, Carbonnière and Marais du Vigueirat, which are $\sim 45 \mathrm{~km}$ apart (Fig. 1). In these areas, marshes are flooded either naturally by rain or artificially by irrigation. The salinity and dryness of the soil have a strong influence on natural vegetation type within the marshes (Dervieux et al., 2002).

'Carbonnière' $\left(4^{\circ} 13^{\prime} \mathrm{E}, 43^{\circ} 35^{\prime} \mathrm{N}\right)$ consists of different types of marshes and some arable paddies. Human presence is clearly evident, both in the residential areas and in the extensive activities that take place, which include tourism, agriculture (including wine growing and cultivated reedbeds) and animal husbandry (cattle and horse breeding) and hunting, etc. Mosquito control is practised in Carbonnière, mainly against Aedes caspius (Pallas), an extreme nuisance species because of its aggressive daytime biting activity, using Bacillus thuringiensis serovar israelensis and temephos.

'Marais du Vigueirat' $\left(4^{\circ} 46^{\prime} \mathrm{E}, 43^{\circ} 30^{\prime} \mathrm{N}\right)$ is a nature reserve, which consists of similar biotopes to Carbonnière. However, on the western border there is a large area of cultivated rice paddies, which provide a greater area of wetland than would occur naturally, especially in the summer months. Human activities and impacts in the reserve are limited and no mosquito control is conducted.

\section{Mosquito sampling}

Adult mosquitoes were captured during March-October 2005. Miniature CDC (Centers for Disease Control) light traps (John W. Hock Co., Gainesville, FL, U.S.A.) (Sudia \& Chamberlain, 1962) baited with $\mathrm{CO}_{2}$ dry ice, in eight locations in each of the two areas, overnight (19.00-10.00 hours) for two consecutive nights, once every 2 weeks. Locations for the CDC light traps were chosen with the aim of sampling the range of biotopes that were accessible.

\section{Processing of mosquitoes}

Mosquitoes were identified using morphological characteristics (Schaffner et al., 2001). When more than 100 females were captured per light trap, a random sample of 100 mosquitoes was identified, and the number of mosquitoes per species was extrapolated. Specimens belonging to the Anopheles maculipennis Meigen complex were identified to species level using speciesspecific multiplex polymerase chain reaction (PCR) (Proft et al., 1999). For each night, the numbers of mosquitoes per species, caught from the eight traps, were added together, and an average was calculated based on the two consecutive nights. Hence, the results show the mean number of mosquitoes collected in the area from the eight traps per night.

\section{Environmental data}

Climatic data, including daily mean temperature and rainfall, were provided by Météo France, the French national meteorological centre, and were recorded at two different stations: Aigues Mortes $\left(4^{\circ} 12^{\prime} \mathrm{E}, 43^{\circ} 32^{\prime} \mathrm{N}\right)$, located $7 \mathrm{~km}$ from the Carbonnière site, and Tour du Vallat $\left(4^{\circ} 41^{\prime} \mathrm{E}, 43^{\circ} 30^{\prime} \mathrm{N}\right)$, located $9 \mathrm{~km}$ from Marais du Vigueirat. Data concerning artificial or natural flooding, in rice fields or marshes, were recorded during mosquito collection periods and completed by surveys among local people.

\section{Statistical analysis}

Median abundance (the date dividing the first half of the total number of collected mosquitoes from the second half) has been calculated for every species in both location. Pearson correlations (linear correlation) were tested between the mean number of mosquitoes collected per species per night and climate data (the mean temperature and cumulative rainfall registered for the period 14-28 days before the date of mosquito sampling).

\section{Results}

A total of 670614 mosquitoes belonging to 16 species were caught in both areas. Numbers of mosquitoes caught per study area and per species are reported in Table 1. Only two species from the Anopheles maculipennis complex were identified: Anopheles melanoon Hackett and Anopheles atropravus Van Thiel. Of these, Anopheles atroparvus had been the main malaria vector in the past when malaria was endemic in the Camargue. Only four specimens were caught because the species is currently rare, indicating that its potential future role as a malaria vector is insignificant (Rioux, 1958; Ponçon et al., 2007a). Anopheles hyrcanus (Pallas), which is currently the main potential malaria vector (Ponçon et al., 2007a), was the third most abundant species. Culex pipiens L. and Culex modestus Ficalbi, the fourth and second most abundant species, respectively, are considered to be the main WNV vectors (Balenghien et al., 2007). Aedes caspius, Cx modestus, Cx pipiens and An. hyrcanus were the main species collected, representing $98.7 \%$ of all mosquitoes collected.

The mean number of mosquitoes caught per night and the median abundance of $C x$ modestus, Cx pipiens, An. hyrcanus 


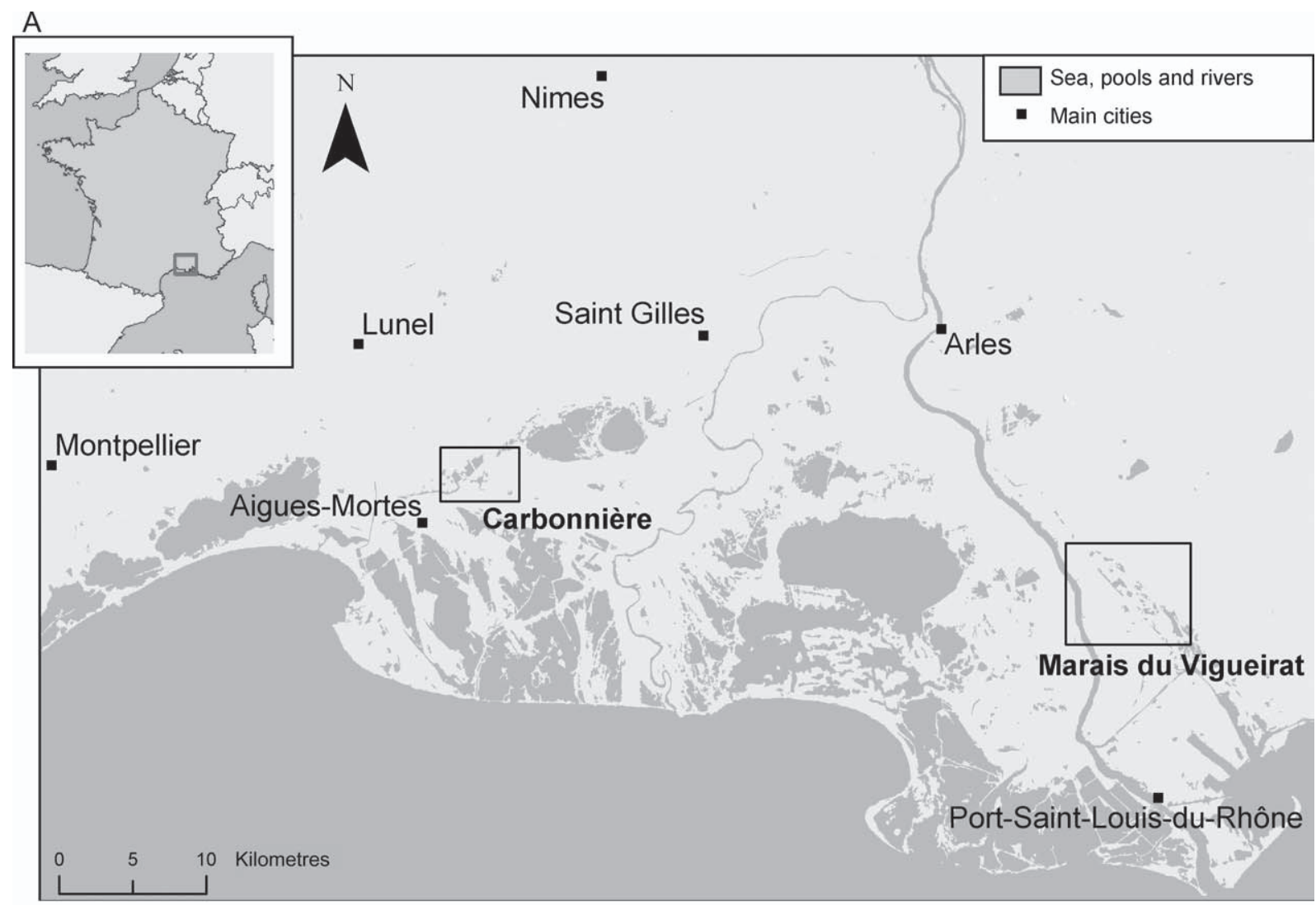

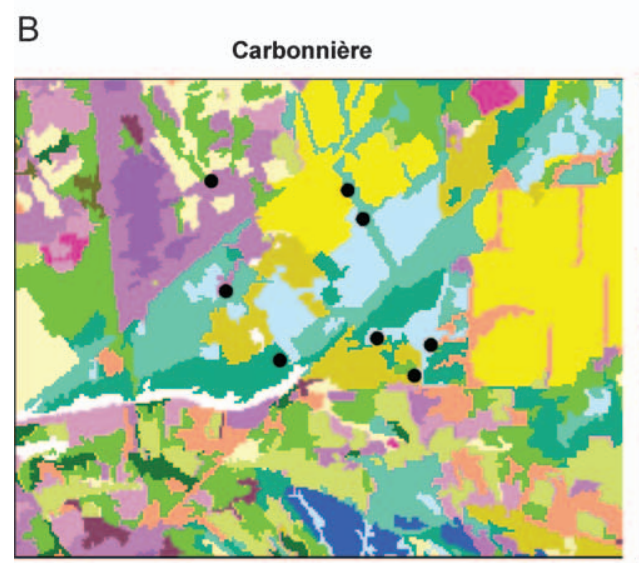

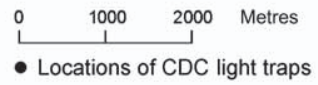

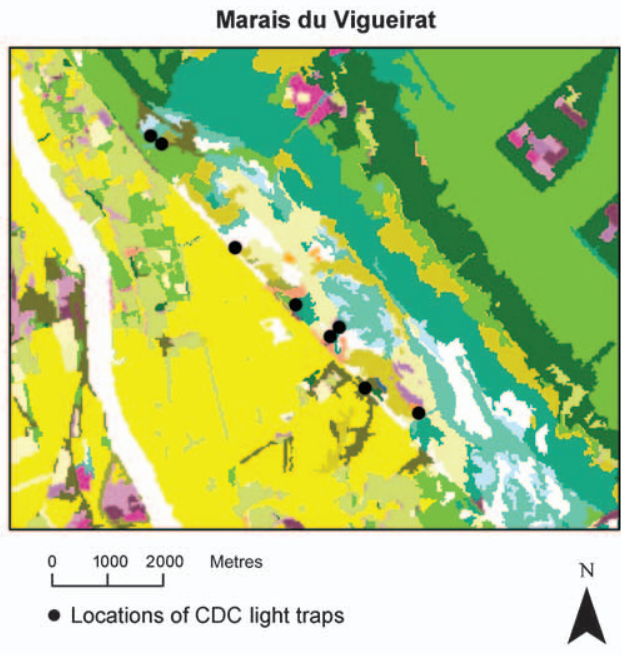

Land cover map

$\square$ Bare soil

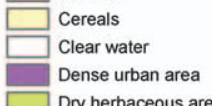

$\square$ Dry herbaceous areas

Fallow land

Floating aquatic vegetation

Forest

Fruit trees

Hedges

Lagoon

Marshes with scirpus and rushes

Mud flat

Reed beds

Rice fields

Riparian forest

Rush prairies never flooded

Rush wetland temporarily flooded

Salt bare soil

Salt marsh vegetation

Scrubland

Suburban and rural area

Vineyard

Fig. 1. Locations of (A) the Camargue and field study areas, and (B) CDC light traps in both field study areas, with descriptions of land cover.

and Ae. caspius, cumulative rainfall and mean temperature for the 2 weeks preceding the sampling day for each area are presented in Figs 2 and 3. Ponçon et al. (2007a) previously reported a detailed study of the population dynamics and biology of Anopheles populations in the Camargue. In the present study, the population dynamics of a range of species are presented to highlight differences between the patterns of catches of the main mosquito species and the impact of different environmental factors.

The mean temperature and the mean catch size of An. hyrcanus were significantly correlated at Carbonnière $(P<0.05)$ (Fig. 2A). At Marais du Vigueirat, the mean catch size of An. hyrcanus, and $C x$ pipiens were significantly correlated with the mean temperature $(P<0.001 ; P<0.05$, respectively) (Fig. 2B) 
Table 1. Total number of mosquitoes collected per species and area.

\begin{tabular}{|c|c|c|c|}
\hline & $\begin{array}{c}\text { Carbonnière } \\
\text { (243 trap nights) }\end{array}$ & $\begin{array}{l}\text { Marais du Vigueirat } \\
\text { (239 trap nights) }\end{array}$ & Total \\
\hline An. (Ano.) algeriensis Theobald & 0 & 170 & 170 \\
\hline An. (Ano.) atroparvus Van Thiel & 4 & 0 & 4 \\
\hline An. (Ano.) hyrcanus (Pallas) & 5551 & 111931 & 117482 \\
\hline An. (Ano.) melanoon Hackett & 232 & 1806 & 2038 \\
\hline Ae. (Och.) caspius (Pallas) & 42432 & 221740 & 264172 \\
\hline Ae. (Och.) detritus* (Haliday) & 44 & 3936 & 3980 \\
\hline Ae. (Fin.) geniculatus (Olivier) & 44 & 50 & 94 \\
\hline Ae. (Rus.) rusticus (Rossi) & 0 & 21 & 21 \\
\hline Ae. (Adm.) vexans (Meigen) & 45 & 1189 & 1234 \\
\hline Cq. (Coq.) richiardii (Ficalbi) & 30 & 872 & 902 \\
\hline Cs. (Cus.) subochrea (Edwards) & 0 & 51 & 51 \\
\hline Cs. (Cus.) annulata (Schrank) & 5 & 42 & 47 \\
\hline$C x$ (Bar.) modestus Ficalbi & 25480 & 163921 & 189401 \\
\hline Cx $($ Cux $)$ pipiens $\mathrm{L}$. & 29739 & 60975 & 90714 \\
\hline Cx $($ Cux $)$ theileri Theobald & 0 & 3 & 3 \\
\hline Ur. (Psc.) unguiculata Edwards & 8 & 293 & 301 \\
\hline Total & 103614 & 567000 & 670614 \\
\hline
\end{tabular}

*and/or Ae. (Och.) coluzzii.

and the catch size of Ae. caspius and cumulative rainfall were significantly correlated at Marais du Vigueirat $(P<0.01)$ (Fig. 3B).

Some species were found only during a short period: Aedes vexans (Meigen) was present only during September-October, Aedes detritus s.l. (Ae. detritus (Haliday) and/or Aedes coluzzii Rioux, Guilvard \& Pasteur) only in October, and Coquillettidia richiardii (Ficalbi) only at the beginning of the summer.

\section{Discussion}

Although the total numbers of mosquitoes collected in each area were very different, the four most abundant of the 16 species present were the same in both areas. The proportions of each species differed, however, depending on biotopes and human activities. The 12 remaining species represented only $1.3 \%$ of the total catches, which may be related to the rareness of particular breeding sites in the Camargue in 2005, or possibly to the species-specific efficacy of CDC light traps baited with $\mathrm{CO}_{2}$ for sampling.

In general, the reproduction strategies of a particular genus of mosquitoes interacts differentially with environmental variables, such as short-term rainfall patterns and seasonal weather patterns. For example, the eggs of Anopheles and Culex cannot withstand desiccation, hence exceptionally dry periods depress the population until the availability of free-standing water enables surviving adult females to lay eggs successfully again, and populations slowly increase. In these genera, females overwinter in a state of diapause and the few surviving females lay eggs in spring when leaving the diapause state, which begin the next generation. By contrast, Aedes species lay eggs which resist desiccation and hatch whenever flooding occurs if eggs are not in a winter diapause state (Kettle, 1995). Consequently, the population density of Aedes responds more quickly to successive periods of artificial or natural flooding and dryness.

Anopheles hyrcanus has recently been found to be increasing in abundance in the Camargue and to have relatively high human biting rates, which suggest that it is currently the only mosquito likely to play a role in malaria transmission (Ponçon et al., 2007a,b). Moreover, it is currently responsible for malaria transmission in the north of Afghanistan (Onori et al., 1975; Faulde et al., 2007). During this study, the population dynamics of $A n$. hyrcanus were similar at the two sites. Both populations increased in the middle of June, reached a peak near the middle of August and decreased dramatically from the middle of September. This pattern was related to the condition of the rice fields, as these are the main breeding sites for this species, especially from mid-June to the end of August (Rioux, 1958; Ponçon et al., 2007a). During this period rice fields were continuously flooded and rice plants covered the surface of the water. Moreover, the increase in mean temperature throughout the summer increased the rate of larval development and hence the rate of population growth (Jetten \& Takken, 1994). Before midJune, the rice fields, which had been flooded since May, were drained two or three times and rice plants no longer covered the surface, thereby reducing the survivorship of Anopheles mosquitoes. None of the following factors - wind, temperature, humidity, intensity of moonlight, modification of Anopheles breeding sites or larviciding - were associated with the drop in An. hyrcanus density at the end of July in either area. Finally, water was removed from the paddies at the end of August, and, consequently, An. hyrcanus populations began decreasing soon afterwards.

Culex modestus is considered to be the main WNV vector, based on abundance, feeding behaviour (Mouchet et al., 1970; Balenghien et al., 2006), previous WNV isolations (Hannoun et al., 1964) and recent experimental transmission (Balenghien et al., 2007). It presented a similar pattern in both areas, being 
A

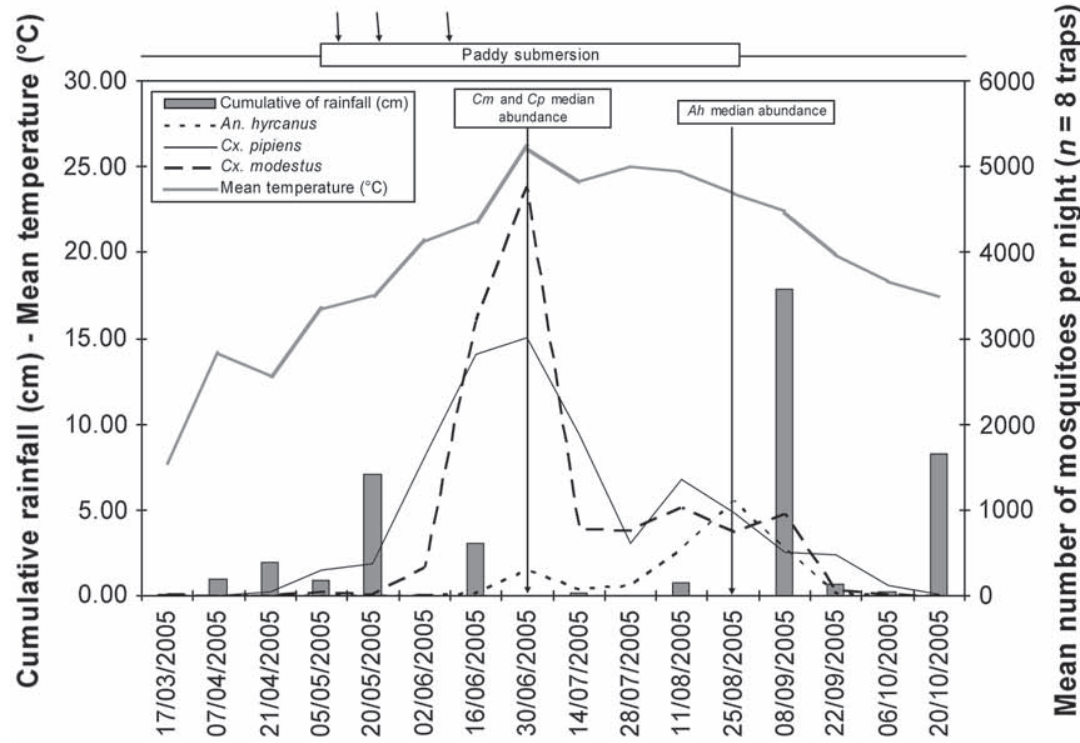

B

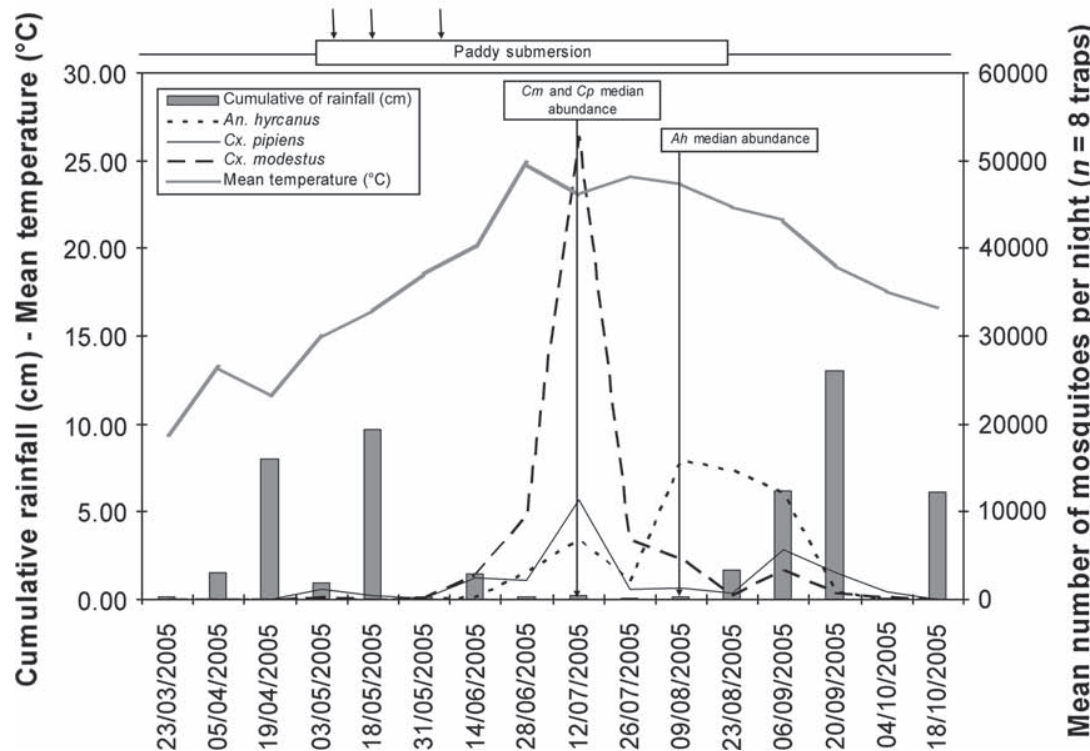

Fig. 2. Seasonal changes in trap catches of Anopheles hyrcanus, Culex modestus and Culex pipiens, and rainfall and temperatures at (A) Carbonnière and (B) Marais du Vigueirat during March-October 2005. Paddy submersion is indicated at the top of each figure, and arrows indicate periods when water was drained from the paddies. Mean number of mosquitoes collected from the eight traps per night is shown. Climate data represent cumulative rainfall and mean temperatures for the two weeks before the samples were collected. The median abundance indicates the date dividing the first half of the total number of collected mosquitoes from the second half. Cm, Culex modestus; Cp, Culex pipiens; Ah, Anopheles hyrcanus. most abundant near the beginning of the summer. Reed marshes constituted the main natural breeding site for $C x$ modestus in spring and early summer 2005, when these areas were naturally flooded. Post-overwintering females initiated population growth in the spring, which rose with increasing air temperatures (Mouchet et al., 1970; Ludwig et al., 2005). In both areas, natural breeding sites dried up during the course of the summer, with little rainfall from late May to early September, which might explain the spectacular drop in $C x$ modestus catch sizes at the end of July and maintenance at a low level throughout August.
Although this species has been described as highly prolific in paddies in the Camargue (Mouchet et al., 1970), the catch size was low in the late summer, especially compared with that of An. hyrcanus, the main paddy breeder. This may be related, at least in part, to the shorter distance over which $C x$ modestus adults could disperse from paddies to be captured by the CDC traps, which were located $\sim 400 \mathrm{~m}$ from the paddies. Although September rains filled the reed marshes, unfavourable climatic autumn conditions did not allow huge populations to develop and females went into over-wintering diapause in October 
A

Fig. 3. Seasonal changes in trap catches of Aedes caspius, rainfall and temperatures at (A) Carbonnière and (B) Marais du Vigueirat during March-October 2005. Mean number of mosquitoes collected from the eight traps per night is shown for each day of capture. Climate data represent cumulative rainfall and mean temperatures for the two weeks before the samples were collected. AF, artificial flooding conducted in marshes. The median abundance indicates the date dividing the first half of the total number of collected mosquitoes from the second half. Ac, Aedes caspius.
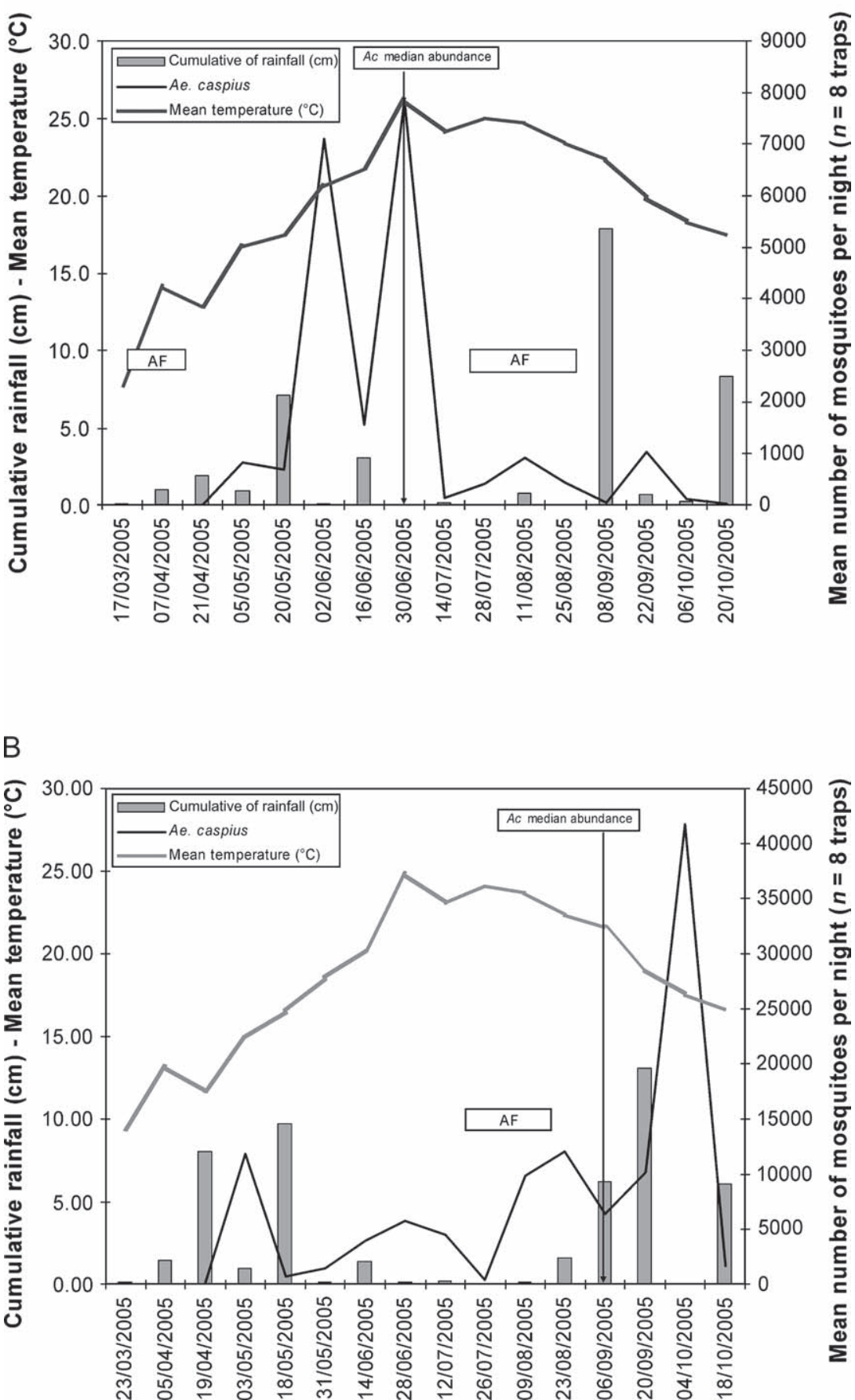

(Mouchet et al., 1970), and hence mosquito populations decreased.

Culex pipiens is also considered to be a WNV vector in the Camargue, based on abundance and feeding behaviour (Balenghien et al., 2006). Moreover, although no WNV isolation has been reported from Cx pipiens in the Camargue, it has been found to be naturally infected with WNV in the Czech Republic (Hubalek et al., 1998), Portugal (Esteves et al., 2005),
Romania (Savage et al., 1999) and Russia (Fyodorova et al., 2006). The ability of this species to transmit WNV by bloodfeeding has been established in several countries (Tahori et al., 1955; Hurlbut, 1956; Turell et al., 2000; Goddard et al., 2002; Tiawsirisup et al., 2005). In the present study, it presented nearly the same pattern as Cx modestus, although it has been reported to breed in every type of fresh-water breeding site, including marshes, natural and artificial pools, flooded pastures and rice 
fields, and also in salt marshes (Rioux, 1958; Schaffner et al., 2001).

The three main factors that appear to have determined the abundance of Ae. caspius in both areas in the Camargue in 2005 were: the characteristics of the breeding sites; the degree and repetition of flooding, and the extent of larvicide treatments. Previous studies have shown that Ae. caspius females lay eggs predominantly in the marshes in the Camargue, unlike in Italy, where rice cultivation is responsible for high populations of this nuisance species (Gabinaud et al., 1975; Bellini et al., 1994). It has been reported that during January-October, Ae. caspius females appear within 2 weeks following the natural or artificial flooding of breeding sites, corresponding to the time required to complete development from egg through all larval instars (Gabinaud et al., 1975). In the study reported here, an increase in rainfall induced massive natural flooding in May and October and appears to have been responsible for the sharp increase in abundance of Ae. caspius at Marais du Vigueirat. Moreover, artificial flooding conducted near Marais du Vigueirat for human activities (e.g. hunting and nature conservation) was responsible for catches of Ae. caspius during August, as has been previously observed in the Camargue (Balenghien et al., 2006).

Larviciding against Ae. caspius reduced catches dramatically. Catches of Ae. caspius at Carbonnière were low after artificial flooding conducted at the beginning of April, at the end of July and at the beginning of August. When significant amounts of rain occurred at Carbonnière in May and June, large flooded areas were successfully treated with larvicides by aircraft application. However, smaller breeding sites, which are less accessible but very abundant and productive, were not treated with larvicides. This resulted in significant local increases in the populations in June (F. Schaffner, personal communication). However, flooding of breeding sites following heavy rains in September did not result in increased numbers of Ae. caspius, even though no larviciding took place. It is likely that larvae were washed out by the inundations of water produced by heavy rain. Finally, the overall pattern of catches for Ae. caspius, as reflected by median abundance, differed between the two areas as a result of differences in the timing and impact of flooding and larvicidal treatments.

The population dynamics of nuisance mosquitoes and potential vectors of malaria and WNV in the Camargue clearly depend on many climatic factors (e.g. temperature, rainfall and season) and anthropogenic factors (e.g. water management in relation to landscape use and mosquito control activities). A clearer understanding of these dynamics is needed to enable us to model and predict changes in the entomological risk factors contributing to malaria or WNV disease transmission.

\section{Acknowledgements}

We thank Michel Babinot, Olivier Bardin, Didier Caire, Dominique Gindre, Nathalie Barras, Christophe Lagneau, Claire Duchet, Alexandre Carron, Charles Jeannin, Cécile Ivanes and Nicolas Sidos from Entente Interdépartementale pour la Démoustication for information and support; Annelise Tran from Cirad for geographic support; Jérémiah Petit from the Syndicat
Mixte pour la Protection et la Gestion de la Camargue Gardoise; Jean Laurent Lucchesi, Nathalie Hecker, Grégoire Massez, Jean Baptiste Nogues and Mathieu Chambouleyron from the Marais $\mathrm{du}$ Vigueirat Association for hospitality and information; Cyrille Thomas from the French Rice Centre for information on paddies, and Alain Dervieux for his knowledge of the Camargue. This work was supported by the Institut de Recherche pour le Développement and was partially funded by the French Ministry of Agriculture and EU grant GOCE-2003-010284 EDEN (the paper is catalogued by the EDEN Steering Committee as EDEN0061 [http://www.eden-fp6project.net/]). The contents of this publication are the sole responsibility of the authors and can in no way be taken to reflect the views of the EU.

\section{References}

Armengaud, A., Legros, F., Quatresous, I. et al. (2006) A case of autochthonous Plasmodium vivax malaria, Corsica, November 2006. EuroSurveillance, 11, E061116.3.

Balenghien, T., Fouque, F., Sabatier, P. \& Bicout, D.J. (2006) Horse, bird, and human-seeking behaviour and seasonal abundance of mosquitoes in a West Nile virus focus of southern France. Journal of Medical Entomology, 43, 936-946.

Balenghien, T., Vazeille, M., Reiter, P., Schaffner, F., Zeller, H. \& Bicout, D.J. (2007) Evidence of the laboratory vector competence of Culex modestus Ficalbi for West Nile virus. Journal of the American Mosquito Control Association, 23, 233-236.

Bellini, R., Veronesi, R. \& Rizzoli, M. (1994) Efficacy of various fish species (Carassius auratus [L.], Cyprinus carpio [L.], Gambusia affinis [Baird and Girard]) in the control of rice field mosquitoes in Northern Italy. Bulletin of the Society for Vector Ecology, 19, 87-99.

Dervieux, A., Allard, P., Naizot, T. \& Auda, Y. (2002) La Camargue est-elle un polder? Changement et stabilité dans le delta du Rhône depuis le début du XIXème siècle. Equilibre et Ruptures dans les Écosystèmes durant les 20 derniers Millénaires en Europe de l'Ouest. Actes du colloque international de Besançon (ed. by H. Richard and A. Vignot), vol. 1, pp. 315-329. Presses Universitaires FrancComtoises, Besançon.

Doudier, B., Bogreau, H., DeVries, A. et al. (2007) Autochthonous malaria from Marseille to Minneapolis? Emerging Infectious Diseases, 13, 1236-1238.

Esteves, A., Almeida, A.P., Galao, R.P. et al. (2005) West Nile virus in Southern Portugal, 2004. Vector-Borne and Zoonotic Diseases, 5, $410-413$.

Faulde, M.K., Hoffmann, R., Fazilat, K.M. \& Hoerauft, A. (2007) Malaria re-emergence in Northern Afghanistan. Emerging Infectious Diseases, 13, 1402-1404.

Fyodorova, M.V., Savage, H.M., Lopatina, J.V., Bulgakova, T.A., Ivanitsky, A.V., Platonova, O.V. \& Platonov, A.E. (2006) Evaluation of potential West Nile virus vectors in Volgograd region, Russia, 2003 (Diptera: Culicidae): species composition, bloodmeal host utilization, and virus infection rates of mosquitoes. Journal of Medical Entomology, 43, 552-563.

Gabinaud, A., Croset, H., Cousserans, J. \& Rioux, J.A. (1975) Ecologie de deux Aedes halophiles, Aedes (O.) caspius (Pallas, 1771) et Aedes (O.) detritus (Haliday, 1833) dans le midi de la France. I. Structure chorinique et critères d'identification des deux espèces au stade oeuf. Annales de Parasitologie Humaine et Comparée, 50, 123-130.

Goddard, L.B., Roth, A.E., Reisen, W.K. \& Scott, T.W. (2002) Vector competence of California mosquitoes for West Nile virus. Emerging Infectious Diseases, 8, 1385-1391. 
Hannoun, C., Panthier, R., Mouchet, J. \& Eouzan, J.P. (1964) Isolement en France du virus West-Nile à partir de malades et du vecteur Culex modestus Ficalbi. Comptes Rendus Hebdomadaires des Séances de l'Académie des Sciences. Série D: Sciences Naturelles, 259, 4170-4172.

Hubalek, Z., Halouzka, J., Juricova, Z. \& Sebesta, O. (1998) First isolation of mosquito-borne West Nile virus in the Czech Republic. Acta Virologica, 42, 119-120.

Hurlbut, H.S. (1956) West Nile virus infection in arthropods. American Journal of Tropical Medicine and Hygiene, 5, 76-85.

Jetten, T.H. \& Takken, W. (1994) Anophelism without malaria in Europe. A review of the ecology and distribution of the genus Anopheles in Europe. Landbouwuniversiteit Wageningen (Wageningen Agricultural University), Wageningen, the Netherlands.

Kettle, D.S. (1995) Medical and Veterinary Entomology, pp. 116-117 CAB International, Wallingford, U.K.

Ludwig, A., Bicout, D.J., Chalvet-Monfray, K. \& Sabatier, P. (2005) Modélisation de l'agressivité de Culex modestus, vecteur potentiel de West-Nile en Camargue, en fonction de données météorologiques. Environnement, Risques et Santé, 4, 109-113.

Mouchet, J., Rageau, J., Laumond, C. et al. (1970) Epidémiologie du virus West Nile: étude d'un foyer en Camargue. V. Le vecteur: Culex modestus Ficalbi Diptera ; Culicidae. Annales de l'Institut Pasteur, 118, 839-855.

Onori, E., Nushin, M.K., Cullen, J.E., Yakubi, G.H., Mohammed, K. \& Christal, F.A. (1975) An epidemiological assessment of the residual effect of DDT on Anopheles hyrcanus s.l. and An. pulcherrimus (Theobald) in the North Eastern region of Afghanistan. Transactions of the Royal Society of Tropical Medicine and Hygiene, 69, 236-242.

Ponçon, N., Balenghien, T., Toty, C. et al. (2007b) Effects of local anthropogenic changes on potential malaria vector Anopheles hyrcanus and the West Nile virus vector Culex modestus Camargue (France). Emerging Infectious Diseases, in press.

Ponçon, N., Toty, C., L'Ambert, G., Le Goff, G., Brengues, C., Schaffner, F. \& Fontenille, D. (2007a) Biology and dynamics of potential malaria vectors in southern France. Malaria Journal, 6, 18.
Proft, J., Maier, W.A. \& Kampen, H. (1999) Identification of six sibling species of the Anopheles maculipennis complex (Diptera: Culicidae) by a polymerase chain reaction assay. Parasitology Research, 85, 837-843.

Rioux, J.A. (1958) Les Culicidés du 'Midi' Méditerranéen, Vol. 35. Editions Paul Lechevalier, Paris.

Rodhain, F. \& Charmot, G. (1982) Evaluation des risques de reprise de transmission du paludisme en France. Médecine et Maladies Infectieuses, 12, 231-236.

Savage, H.M., Ceianu, C., Nicolescu, G. et al. (1999) Entomologic and avian investigations of an epidemic of West Nile fever in Romania in 1996, with serologic and molecular characterization of a virus isolate from mosquitoes. American Journal of Tropical Medicine and Hygiene, 61, 600-611.

Schaffner, F., Angel, G., Geoffroy, B., Hervy, J.-P., Rhaeim, A. \& Brunhes, J. (2001) The Mosquitoes of Europe. IRD Éditions and EID Méditerranée, Paris, France.

Sudia, W.D. \& Chamberlain, R.W. (1962) Battery-operated light trap, an improved model. Mosquito News, 22, 126-129.

Tahori, A.S., Sterk, V.V. \& Goldblum, M. (1955) Studies on the dynamics of experimental transmission of West Nile virus by Culex modestus. American Journal of Tropical Medicine and Hygiene, $\mathbf{4}$ 1015-1027.

Tiawsirisup, S., Platt, K.B., Evans, R.B. \& Rowley, W.A. (2005) A comparision of West Nile virus transmission by Ochlerotatus trivittatus (COQ.), Culex pipiens (L.), and Aedes albopictus (Skuse). VectorBorne and Zoonotic Diseases, 5, 40-47.

Turell, M.J., O'Guinn, M. \& Oliver, J. (2000) Potential for New York mosquitoes to transmit West Nile virus. American Journal of Tropical Medicine and Hygiene, 62, 413-414.

Zeller, H.G. \& Schuffenecker, I. (2004) West Nile virus: an overview of its spread in Europe and the Mediterranean basin in contrast to its spread in the Americas. European Journal of Clinical Microbiology and Infectious Diseases, 23, 147-156.

Accepted 14 September 2007 